\title{
Smart Solution to Towing Vehicles System
}

\author{
Piyush Jaju \\ Department of Computer Engineering \\ S.R.E.S's College of Engineering, Kopargaon \\ SPPU, India. \\ Pooja Dhiwar \\ Department of Computer Engineering \\ S.R.E.S's College of Engineering, Kopargaon \\ Kopargaon \\ SPPU, India.
}

\author{
Komal Batole \\ Department of Computer Engineering \\ S.R.E.S's College of Engineering, Kopargaon \\ SPPU, India.
}

\author{
Sunita Dhanwate \\ Department of Computer Engineering \\ S.R.E.S's College of Engineering, \\ SPPU, India.
}

\begin{abstract}
It is necessary to digitalize the Government for making India corruption free with the help of information and communication technology (ICT) along with internet to achieve better government system by providing public services and processing internal works in suitable, cost effective and customer leaning manner. E-police system is also an egovernment related services which makes the communication process between public and police more efficient. Though epolice system is not a new thing in developed countries, but it is new for developing countries like India. Our system will definitely help to solve some issues which are currently faced by vehicle owners and towing agents.
\end{abstract}

\section{General Terms}

Number Plate Recognition,

Android, Resolution, Edge Detection

\section{Keywords}

Towing Vehicle System, Candidate Area Extraction, Vehicle Number Plate Detection

\section{INTRODUCTION}

In India, it is observed that, traffic police tow or carry abandoned vehicles without notifying the vehicle owner. Person gets panic when he or she came to know that his or her vehicle is misplaced for a long time. Even towing agent don't give exact information about which police station the owner should contact. Other problem is towing agents demand huge amount of money to free vehicle. Basically, owner has no issues if his or her vehicle is getting carried by towing agents, but he or she wanted the information of the same. So, there is a need for such a system which can help the vehicle owner, traffic police and towing contractor to solve all types of problems like tracing tow vehicle location, etc. This project will be an integrated platform for these three types of users such as vehicle owner, traffic police admin and towing contractor. We will provide a good Solution to this problem via integrated this application with image processing, mobile computing and advance web service technologies.

\section{LITERATURE SURVEY}

Vehicle Number Plate Detection (VNPD) System contains three basic modules such as Image pre-processing, candidate area extraction and character recognition. In pre-processing the image is being loaded and converted to gray or binary format. In candidate area extraction, detection of number plate area and segmentation of character is carried out. In character recognition, template matching and retrieval of character is performed [1]. Super resolution is a technique which is used to enhance visual quality of a sequence of low image. The optical character recognition technique acquires the text from super resolution image of vehicle number plate and it compares with the Regional Transport Offices (RTO) database and then it display the details of the vehicle such as owner's name, vehicle registration, etc. [2]. System is based on client server architecture. towing agent has to take the photo using a smart phone, which will be sent to the server. Server extracts number from images using number plate recognition technique, then server tracks vehicle owner information on the basis of vehicle number. Server sends a notification to user [3]. A mapping function from Low Resolution (LR) patches to High resolution (HR) patches is learnt by a local regression algorithm called sparse support regression, which can be constructed from the support basis of LR-HR dictionary. Also to preserve the geometrical structure of image patch dictionary, which is critical for reducing artifacts and obtain better visual quality [4]. Images of the rare end of car are considered. The license plate is extract from the whole image and segmentation is done in order to extract the characters from the image. The characters are recognized from the image and the authorized number plate is displayed as a result [5].

\section{EXISTING SYSTEM}

Today in India, if we parked our vehicle in no-parking area, towing agent will take the vehicle to the police station without notifying the vehicle owner and in cities, there are many police stations, so user will be getting confused about which police station he should visit and he will get panic. Generally the vehicle owner will not park his vehicle in no-parking area if the area is known to him, he will park in no-parking place only in case if he is doesn't know the area or is going first time in that area. Then in this case if he is not aware about the place then it is very difficult to get the current location of the vehicle. Vehicle owner will have to search for the nearby police stations which are a difficult task in unknown areas. After finding the police station if the vehicle is found there, then towing agent will ask for huge money to release the vehicle without enrolling the case in the records. This will lead to corruption and inconvenience of the vehicle owner. So our system will definitely give better solutions to reduce the tension of the vehicle owner.

\section{PROPOSED SYSTEM}

In our system, towing agent will have to capture the photo of vehicle which is parked in no parking area through the application instead of capturing it by simple cameras. After capturing the photo through application captured photo will be sent to the server, it will upload that on our website and will proceed further. Server will convert the RGB image to Gray scale format. After that it will convert the gray- scale image to 
the Binary (Black \& White) format. Next stage is edge detection algorithm, here the image which is converted already into the binary format will be taken as input, horizontal and vertical edge detection will be done to identify the number plate area from whole photo (Candidature Area Extraction). After extracting the number plate, system will identify the license number by segmentation of number plate characters and matching them with training dataset one by one. Then after recognizing license number server will find that identified number in the RTO database. When match is found, it will retrieve the contact number and email id of that candidate. Then simply system will generate the notification which will contain nearest police station from where that user can collect his/her car, amount of fine. Server will also generate the receipt of fine. Fine will be calculated on the basis incremental model.

\section{SYSTEM ARCHITECTURE}

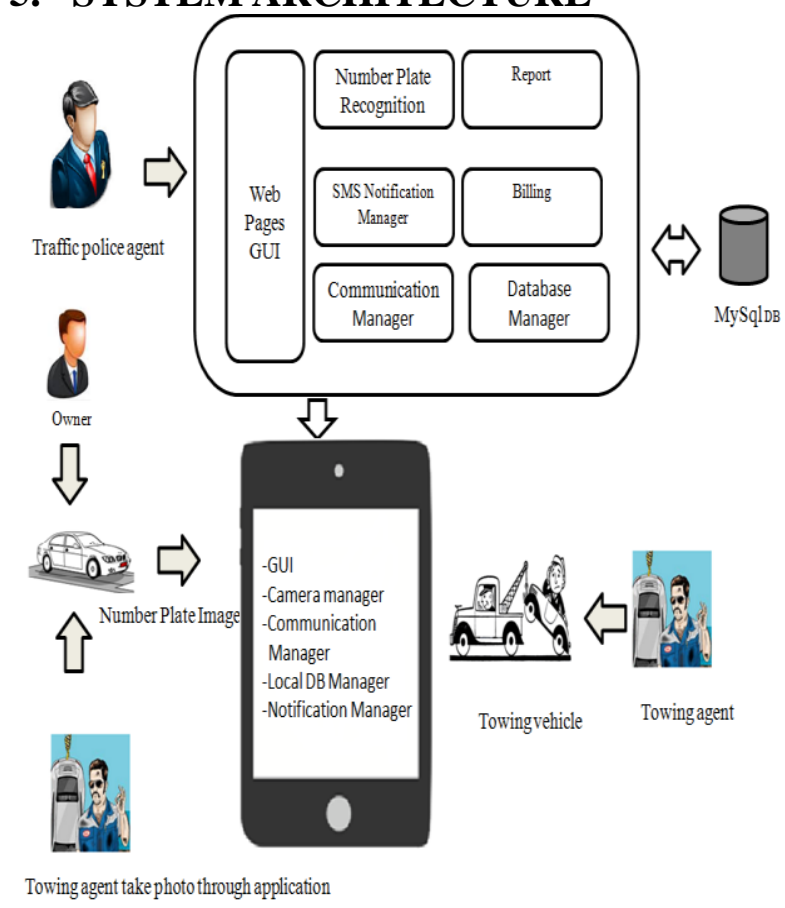

Figure 1: System Architecture

Towing agent will capture photo of car through application. Captured image will be in form of RGB image, server will convert that to Gray scale image using RGB to Gray conversion and later on into binary image (black \& white) with the help of Adaptive Thresholding. Edge detection algorithm will be applied to the binary image for candidate area extraction i.e. finding out number plate from the captured image. Edge detection algorithm involves vertical edge detection and horizontal edge detection. After finding candidate area again edge detection algorithm will separate the characters from number plate and every character will be stored in a template. Every template will be compared with training data set to get the character of same shape, but in some cases the character which is stored in template will vary in size as compared to size of character in training data set, so Mean Square Error algorithm will come in picture. Mean Square Error algorithm will manage the compatibility of the size of characters and will detect characters accurately. In some cases if the number is not detected properly then we can use fuzzy logic i.e. we can alter one of character which is not detected properly and in worst case if the number is not detected by the server then admin can add that number manually. Now the license number will be available and comparison with the RTO database will be done to find the vehicle owner, contact number of vehicle owner will be retrieved and server will generate and send the notification to the respected user Notification will contain current location of the vehicle and payment to be paid.

System representation is given as

$\mathrm{S}=\{\mathrm{I}, \mathrm{P}, \mathrm{R}, \mathrm{O}\}$

\section{Input Set}

I is set of all inputs given to system.

$\mathrm{I}=\left\{\mathrm{I}_{1}, \mathrm{I}_{2}\right\}$

Where,

$\mathrm{I}_{1}=$ Create profile means creating an administration account login with user id and password.

$I_{2}=$ Vehicle number plate image as a input to the system.

\section{Processes}

$\mathrm{P}$ is set of processes followed by the system.

$\mathrm{P}=\left\{\mathrm{P}_{1}, \mathrm{P}_{2}, \mathrm{P}_{3}, \mathrm{P}_{4}, \mathrm{P}_{5}, \mathrm{P}_{6}, \mathrm{P}_{7}, \mathrm{P}_{8}, \mathrm{P}_{9}, \mathrm{P}_{10}, \mathrm{P}_{11}, \mathrm{P}_{12}\right\}$

Where,

$\mathrm{P}_{1}=$ Creating towing agent account with user id and password.

$\mathrm{P}_{2}=$ Add new task for adding a new incident.

$\mathrm{P}_{3}=$ Capture image i.e. capturing photo of the evidence

$\mathrm{P}_{4}=$ Image upload where image is sent to the server.

$\mathrm{P}_{5}=\mathrm{RGB}$ to Gray Scale Transform where RGB image is converted into Gray Scale image.

$\mathrm{P}_{6}=$ Image Binarization is used to convert the Gray Scale image into binary image.

$\mathrm{P}_{7}=$ Edge Detection is used for finding the region of number plate.

$\mathrm{P}_{8}=$ Optical Character Recognition (OCR) used for identifying character from the number plate.

$\mathrm{P}_{9}=$ Identification of vehicle owner means identifying the vehicle owner by comparing the license number with database.

$\mathrm{P}_{10}=$ Distance Calculation is used to calculate the minimum distance from the current location to find the nearest police station.

$\mathrm{P}_{11}=$ Send notification to the vehicle owner about his or her vehicle information.

$\mathrm{P}_{12}=$ Fine calculation where system calculates the amount of fine and check old fine and increment fine and update new fine amount.

Rules

$\mathrm{R}$ is set of rules.

$R=\left\{R_{1}, R_{2}\right\}$

Where,

$\mathrm{R}_{1}=$ Application must be installed on mobile of towing agent.

$\mathrm{R}_{2}=$ Capture evidence image through the application only.

\section{Output Set}

$\mathrm{O}$ is set of output expected from system. 
$\mathrm{O}=\left\{\mathrm{O}_{1}, \mathrm{O}_{2}, \mathrm{O}_{3}\right\}$

Where,

$\mathrm{O}_{1}=$ SMS notification .

$\mathrm{O}_{2}=$ Locate nearest distance police station.

$\mathrm{O}_{3}=$ Generate fine amount .

\section{Venn Diagram}

Venn diagram represents the dependencies between the input, process and output of the project.

This complete view is represented are as following fig.

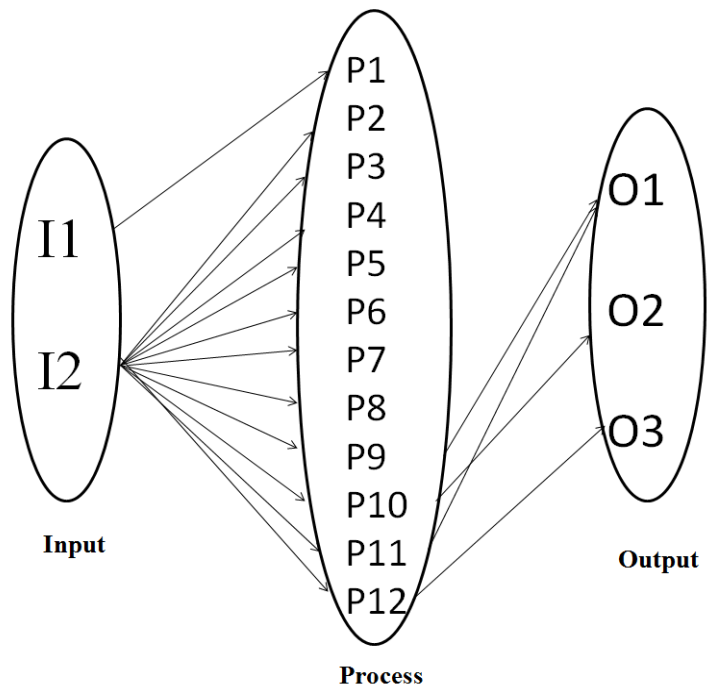

Figure2: Venn diagram

\section{CONCLUSION}

There is a need of a system which will help Vehicle owner, Traffic police and Towing Contractor to solve all types of problems. Our system will provide good solution to Towing Vehicle System via integrating various image processing techniques and effectively reduce complexities in existing system. Our system is going to monitor these changes periodically and take an action to the vehicle owner.

\section{REFERENCES}

[1] Hanit Karwal, Akshay Girdhar, "Vehicle Number Plate Detection System for Indian Vehicles", in IEEE International Conference on Computational Intelligence and Communication Technology, pp. 8-11, 2015.

[2] Balamurugan.G, Sakthivel Punniakodi, Rajeswari.K, Arulalan.V, "Automatic Number Plate Recognition System using Super Resolution Technique", in IEEE International Conference on Computing and Communications Technologies (ICCCT' 15), pp. 1-5, 2015.

[3] Prof. V.S. Phad, Vaishali Dhiman, Bhavik Shah, Shweta Bangad, Akshay Padvi, "Integration of Towing Abandoned Vehicles with Numbers Plate Recognition System", in International Journal for Scientific Research and Development| Vol. 4, Issue 02, pp. 843-844, 2016.

[4] Junjun Jiang, Xiang Ma, Zhihua Cai, Ruimin Hu, "Sparse support regression for image super resolution", in IEEE Translations and content mining are permitted for academic research, pp. 5, 2015.

[5] Riri P Shah, Prof. M.R. Madki "An Approach to License Plate Recognition of Indian Vehicles", in International Journal of Recent Trends in Engineering \& Research, pp 176-179, 2016. 